05

\title{
Исследование термовольтаического эффекта в гетероструктурах на основе твердых растворов $\mathrm{Sm}_{1-x} \mathrm{Gd}_{x} \mathrm{~S}$
}

\author{
(С) В.В. Каминский, М.А. Гревцев, М.М. Казанин, Н.В. Шаренкова \\ Физико-технический институт им. А.Ф. Иоффре РАН, Санкт-Петербург \\ E-mail: vladimir.kaminski@mail.ioffe.ru
}

Поступило в Редакцию 28 апреля 2017 г.

Исследовано влияние на термовольтаический эффект допирования гадолинием моносульфида самария. Эксперименты проведены в интервале температур 300-450 K. Обнаружено и объяснено уменьшение величины эффекта с увеличением содержания гадолиния в гетероструктуре состава $\mathrm{Sm}_{1-x} \mathrm{Gd}_{x} \mathrm{~S}$, где $x$ изменяется от 0 до 0.13. Получены формулы для расчета выходного сигнала в зависимости от величины допирования.

DOI: 10.21883/PJTF.2017.23.45277.16842

Целью настоящей работы является исследование термовольтаического эффекта (ТВЭ) в $\mathrm{SmS}[1,2]$. Следует отметить, что данный эффект наблюдался и в других полупроводниках [3,4]. В частности, было интересно оценить влияние допирования $\mathrm{SmS}$ различными примесями на величину эффекта с целью выявления возможности получения ее максимального значения. Гадолиний был выбран в качестве допирующего элемента, поскольку его добавление в $\mathrm{SmS}$ даже в сравнительно небольших количествах существенно влияет на свойства твердых растворов $\mathrm{Sm}_{1-x} \mathrm{Gd}_{x} \mathrm{~S}$, увеличивая концентрацию электронов в зоне проводимости и уменьшая критическое давление фазового перехода полупроводник-металл [5].

Нами была проведена термодиффузия $\mathrm{Gd}$ в $\mathrm{SmS}$, определен состав образцов, полученных при послойном снятии материала исходного образца, и выполнены измерения ТВЭ на образцах различного состава. Исходный исследуемый образец представлял собой двухслойную структуру из сульфида самария и слоя гадолиния (рис. 1,a). Слой порошка $\mathrm{SmS}$ толщиной $2.92 \mathrm{~mm}$ спрессован со слоем порошка гадолиния толщиной $1 \mathrm{~mm}$. При отжиге в течение $30 \mathrm{~min}$ в вакууме при 


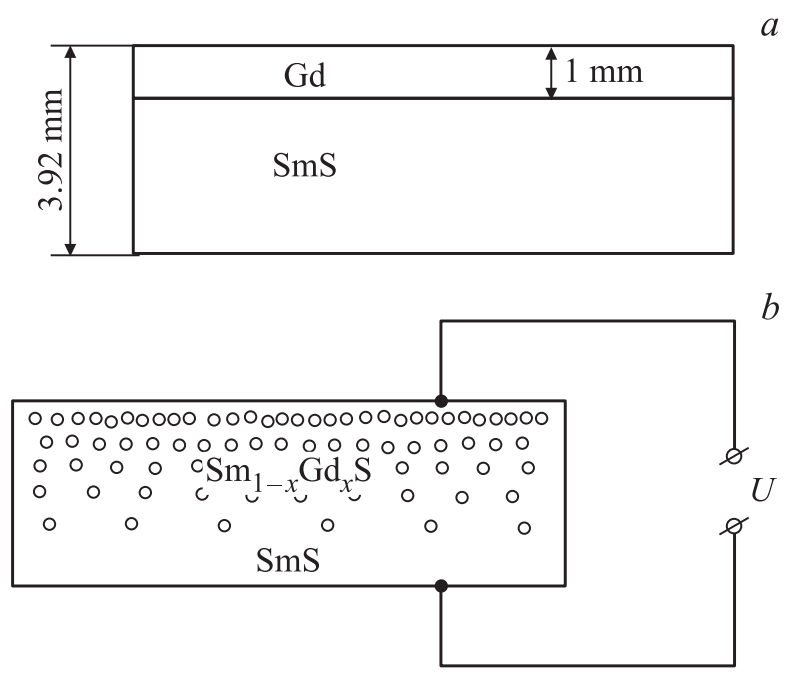

Рис. 1. Исследуемые гетероструктуры. $a-$ схема двухслойного образца $\mathrm{SmS} / \mathrm{Gd}$ до отжига, $b$ - схема измерения выходного сигнала термовольтаического эффекта с гетероструктуры на основе $\mathrm{Sm}_{1-x} \mathrm{Gd}_{x} \mathrm{~S}$.

температуре $T=1240^{\circ} \mathrm{C}$ происходило спекание слоев и диффузия $\mathrm{Gd}$ в $\mathrm{SmS}, \mathrm{S}$ в $\mathrm{Gd}$ и $\mathrm{Sm}$ в $\mathrm{Gd}$.

Состав образца исследовался методом рентгеноструктурного фазового анализа (дифрактометр ДРОН-2, Cu-анод, $K_{\alpha}$-излучение). Путем последовательного сошлифовывания поверхностных слоев со стороны $\mathrm{Cd}$ с помощью рентгеновского анализа поверхности были определены фазовый состав и параметры кристаллической решетки на шлифе полученных таким способом образцов. Анализ дифрактограмм показал, что основной фазой в каждом случае является $\mathrm{Sm}_{1-x} \mathrm{Gd}_{x} \mathrm{~S}$ c разными значениями $x$. Величина $x$ определялась исходя из зависимости параметра кристаллической решетки $a$ от количества гадолиния $x$ в системе твердых растворов $\mathrm{Sm}_{1-x} \mathrm{Gd}_{x} \mathrm{~S}$, представленной на рис. 2, где в области $0.13 \leqslant x \leqslant 0.16$ наблюдается изоструктурный фазовый переход полупроводник-металл. При бо́льших $x$ твердый раствор имеет металлические свойства, при меньших - полупроводниковые [5]. Полученные по этим данным зависимости состава от глубины его

Письма в ЖТФ, 2017, том 43, вып. 23 


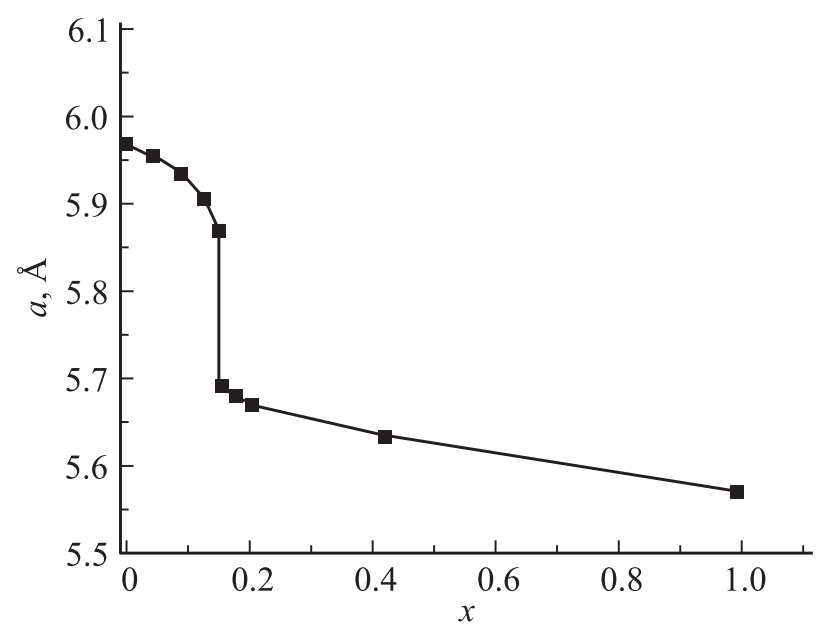

Рис. 2. Зависимость постоянной кристаллической решетки $a$ от количества $\operatorname{Gd} x$ в системе твердых растворов $\mathrm{Sm}_{1-x} \mathrm{Gd}_{x} \mathrm{~S}[5]$.

залегания $h$ относительно исходной поверхности $(h=3.92 \mathrm{~mm})$ представлены на кривой 1 на рис. $3, b$. Эти данные относятся к однофазной полупроводниковой области образца $\mathrm{Sm}_{1-x} \mathrm{Gd}_{x} \mathrm{~S}(x<0.13)$, поскольку исследуемый термовольтаический эффект возможен только в полупроводниках.

Рентгеноструктурный анализ показал, что в верхних слоях образца (рис. 1) присутствуют $\mathrm{GdS}$ и $\mathrm{Sm}_{1-x} \mathrm{Gd}_{x} \mathrm{~S}$, поэтому можно утверждать, что сера и некоторое количество самария продиффундировали в $\mathrm{Gd}$ до самой верхней границы образца. Рентгеновские данные позволили рассчитать коэффициенты диффузии. При оценке коэффициентов диффузии использовалась модель диффузии в полубесконечное тело из неограниченного источника. По результатам расчета коэффициенты диффузии при $T=1240^{\circ} \mathrm{C}$ таковы: для $\mathrm{S}$ в $\mathrm{Gd}-5 \cdot 10^{-6} \mathrm{~cm}^{2} / \mathrm{s}$, для $\mathrm{Sm}$ в $\mathrm{Gd}-1.1 \cdot 10^{-5} \mathrm{~cm}^{2} / \mathrm{s}$, для $\mathrm{Gd}$ в $\mathrm{SmS}-3.6 \cdot 10^{-7} \mathrm{~cm}^{2} / \mathrm{s}$.

Измерения ТВЭ на полученных после каждого цикла шлифовки образцах проводились аналогично тому, как это было сделано в $[6,7]$. На рис. 3, $a$ представлены типичные экспериментальные данные для одного из образцов $(h=2.5 \mathrm{~mm}$, состав шлифованной поверхности 

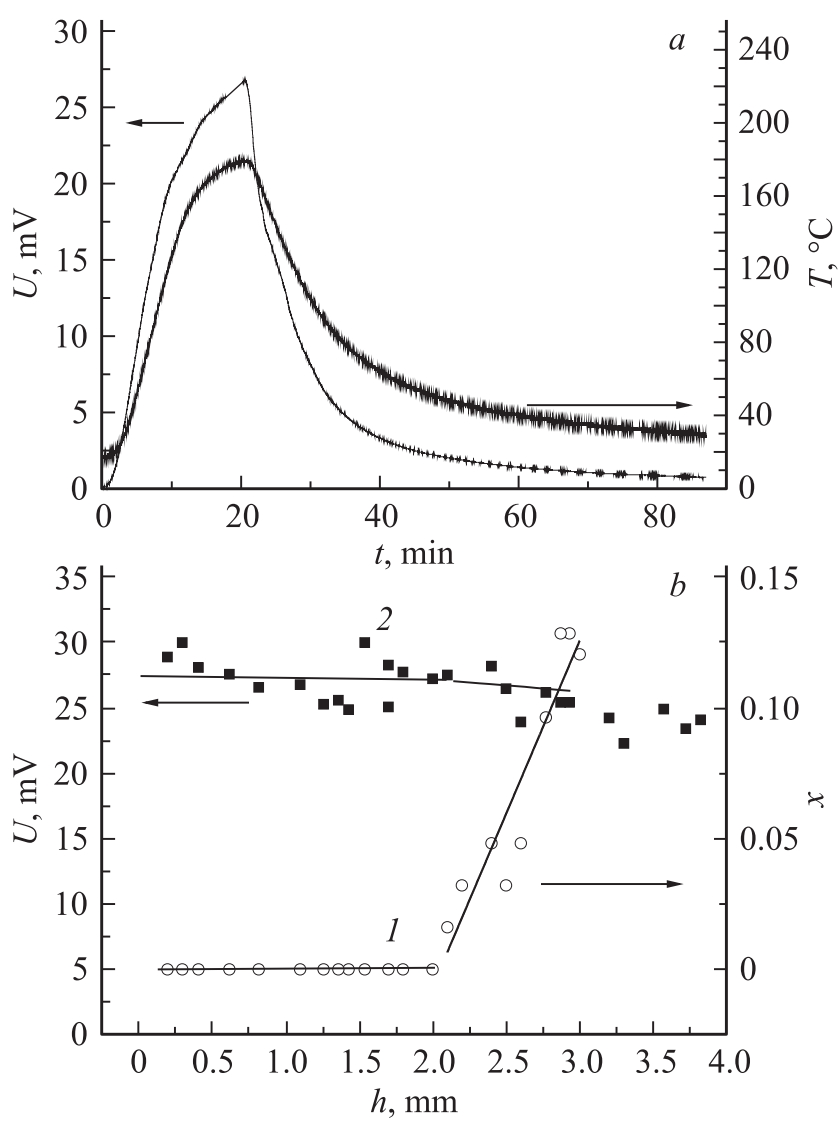

Рис. 3. Измерение термовольтаического эффекта в гетероструктуре на основе $\mathrm{Sm}_{1-x} \mathrm{Gd}_{x} \mathrm{~S} . a-$ типичные зависимости генерируемого напряжения и температуры образца от времени; $b$ - зависимость величины термовольтаического эффекта при $T=450 \mathrm{~K}$ от параметров полученных структур: $1-$ зависимость состава шлифованной поверхности образца от толщины оставшегося после шлифовки материала $h, 2$ - зависимость генерируемого сигнала от $h$.

соответствовал $\mathrm{Sm}_{0.89} \mathrm{Gd}_{0.11} \mathrm{~S}$ ). На рис. $3, b$ (кривая 2) показаны результаты измерений генерируемого при $T=450 \mathrm{~K}$ напряжения на всех полученных шлифовкой образцах в зависимости от их толщины.

5 Письма в ЖТФ, 2017, том 43, вып. 23 
Величина электрического напряжения, генерируемого при термовольтаическом эффекте, описывается следующим соотношением [8]:

$$
U=\frac{k\left(T-T_{0}\right)}{e} \ln \frac{n_{2}}{n_{1}},
$$

где $U-$ выходной сигнал, $n_{1}$ и $n_{2}-$ концентрации электронов проводимости в приконтактных областях, $T_{0}$ и $T$ - начальная и текущая температуры. Если воспользоваться выражением для концентрации электронов проводимости в невырожденном полупроводнике [9], то

$$
n_{1,2}=\sqrt{2 N_{1,2}} \frac{\left(2 \pi m^{*} k T\right)^{3 / 4}}{h^{3 / 2}} \exp \left(-\frac{E_{i}}{k T}\right),
$$

где $E_{i}-$ энергия активации донорных уровней, $N_{1}$ и $N_{2}-$ концентрации донорных уровней в приконтактных областях. В нашем случае контакты присоединены к поверхности образца с составом $\mathrm{SmS}$ и противоположной ей с составом $\mathrm{Sm}_{1-x} \mathrm{Gd}_{x} \mathrm{~S}$ соответственно (рис. $1, b$ ). Поскольку области присоединения контактов при измерении термовольтаического эффекта находятся при одинаковой температуре, величина $n_{2} / n_{1}=\left(N_{2} / N_{1}\right)^{1 / 2}$ и от температуры не зависит.

Для того чтобы оценить значения генерируемого напряжения, необходимо в общем случае знать величины $N_{1}$ и $N_{2}$. Однако в нашем случае можно воспользоваться другими соображениями. За величину $n_{1}$ можно взять типичное для $\mathrm{SmS}$ при $T=300 \mathrm{~K}$ значение: $n_{1}=10^{19} \mathrm{~cm}^{-3}$. Материал противоположной стороны образца был подвергнут механической полировке, переводящей приповерхностный слой $\mathrm{SmS}$ в металлическое состояние [5]. Как показано в [10], переход из полупроводникового в металлическое состояние $\mathrm{SmS}$ при полировке связан с увеличением дефектности приповерхностного слоя образца. Дефектность в прилегающем к металлическому полупроводниковом слое $\mathrm{SmS}$ (величина $N_{2}$ ) близка к критической для перехода в металлическое состояние. Из результатов работы [9] известно, что критическая концентрация электронов проводимости для перехода любых полупроводниковых образцов $\mathrm{SmS}$ в металлическое состояние при $T=300 \mathrm{~K}$ равна $8 \cdot 10^{19} \mathrm{~cm}^{-3}$. Соответствующая этому значению по формуле (2) величина $N_{2}$ и должна фиксироваться в ближайшем к металлической фазе полупроводниковом слое полированного образца $\mathrm{SmS}[10]$. В динамике при повышении температуры образца в рассматриваемом диапазоне температур $(300-450 \mathrm{~K})$ должно сохраняться

Письма в ЖТФ, 2017, том 43, вып. 23 
соотношение $n_{2} / n_{1}=8 \cdot 10^{19} \mathrm{~cm}^{-3} / 1 \cdot 10^{19} \mathrm{~cm}^{-3}=8$. Рассчитанная по формуле (1) при $T-T_{0}=150 \mathrm{~K}$ зависимость сигнала от толщины и состава образца, представленная на рис. $3, b$, хорошо совпадает с экспериментальными данными для всех толщин, при которых образец имеет стехиометрический состав $(0<h<2 \mathrm{~mm}, x=0)$. При $h>2 \mathrm{~mm} x$ имеет значения от 0 до 0.13. В этом диапазоне мы наблюдаем понижение генерируемого напряжения с ростом $h$ и $x$. Такое изменение легко отразить в формуле (1), если учесть тот факт, что при $x>0$ часть ионов $\mathrm{Sm}$ замещается ионами $\mathrm{Gd}$, которые в отличие от ионов $\mathrm{Sm}$ не меняют валентность при повышении температуры и не участвуют в генерации выходного сигнала. Тогда формула (1) приобретает вид

$$
U=\frac{k\left(T-T_{0}\right)}{e} \ln \frac{n_{2} \sqrt{1-x}}{n_{1}},
$$

поскольку $\left(N_{2} / N_{1}\right)^{1 / 2}=n_{2} / n_{1}$, и при уменьшении величины $N_{2}$ в $(1-x)$ раз соответственно и соотношение $n_{2} / n_{1}$ уменьшается в $(1-x)^{1 / 2}$. Рассчитанная по формуле (3) зависимость $U(h)$ при $2<h<3 \mathrm{~mm}$ и $0<x<0.13$ представлена на рис. $3, b$ и также хорошо совпадает с экспериментальными данными. Следует отметить, что в формуле (3) соотношение $n_{2} / n_{1}$ можно заменить соотношением $\left(N_{2} / N_{1}\right)^{1 / 2}$, а для случая малых изменений состава полупроводника в гетероструктуре можно заменить соотношением $\sigma_{2} / \sigma_{1}$, поскольку удельная электропроводность $\sigma=e n u$ и величина подвижности $u$ может быть одинакова по всему объему образца. В разных экспериментах для расчета бывает удобно пользоваться той или иной формулой.

На основе результатов работы можно сделать вывод, что в генерации сигнала термовольтаического эффекта в гетероструктурах на основе $\mathrm{Sm}_{1-x} \mathrm{Gd}_{x} \mathrm{~S}$ принимает участие только ион самария, который в моносульфиде может быть как двух-, так и трехвалентным. Гадолиний, который в моносульфиде может быть только трехвалентным, в генерации сигнала участия не принимает. Можно предположить, что аналогичным образом ведут себя и твердые растворы с $\mathrm{SmS}$ других редкоземельных элементов, которые в моносульфидах трехвалентны. Это составы $\mathrm{Sm}_{1-x} L_{x} \mathrm{~S}$, где $L n=\mathrm{La}, \mathrm{Ce}, \mathrm{Pr}, \mathrm{Nd}, \mathrm{Tb}, \mathrm{Dy}, \mathrm{Ho}, \mathrm{Er}, \mathrm{Tm}, \mathrm{Lu}$. Дело в том, что для всех таких $L n S$ характерна одна и та же схема валентно-нескомпенсированного строения типа $\left(\operatorname{Ln}^{3+} \mathrm{S}^{2-}\right) e^{-}$, когда на ионах $L n$ локализовано такое же число $4 f$-электронов, как и на трехзарядных ионах, а один электрон находится в зоне проводимости [11]. Эта

$5^{*}$ Письма в ЖТФ, 2017, том 43, вып. 23 
конфигурация с температурой не меняется. По-видимому, формула (3) справедлива для всех твердых растворов $\mathrm{Sm}_{1-x} L n_{x} \mathrm{~S}$.

\section{Список литературы}

[1] Казанин М.М., Каминский В.В., Соловьёв С.М. // ЖТФ. 2000. Т. 70. В. 4. C. $136-138$.

[2] Каминский В.В., Соловьёв С.М. // ФТТ. 2011. Т. 43. В. 3. С 423-426.

[3] Пронин И.А., Аверин И.А., Божсинова А.С., Георгиева А.Ц., Димитров Д.Ц., Карманов А.А., Мошников В.А., Папазова К.И., Теруков Е.И., Якушова Н.Д. // Письма в ЖТФ. 2015. Т. 41. В. 19. С. 23-29.

[4] Саидов А.С., Лейдерман А.Ю., Карииев А.Б. // Письма в ЖТФ. 2016. Т. 42. B. 14. C. 21-27.

[5] Оскотский В.С., Смирнов И.А. // Редкоземельные полупроводники. Л.: Наука, 1977. С. 105-145.

[6] Каминский В.В., Казанин М.М., Соловьёв С.М., Голубков А.В. // ЖТФ. 2012. T. 82. В. 6. С. $142-144$.

[7] Каминский В.В., Казанин М.М., Романова М.В., Каменская Г.А., Шаренкова Н.В. // ФТП. 2016. Т. 50. В. 9. С. 1163-1166.

[8] Каминский В.В., Степанов Н.Н., Соловьёв С.М. // Физика и техника высоких давлений. 2015. Т. 25. № 3-4. С. 74-81.

[9] Гребинский С.И., Каминский В.В., Рябов А.В., Степанов Н.Н. // ФТТ. 1982. T. 24. B. 6. C. $1874-1876$.

[10] Шаренкова Н.Н., Каминский В.В., Голубков А.В., Васильев Л.Н., Каменская Г.А. // ФТТ. 2005. Т. 47. В. 4. С. 598-602.

[11] Голубков А.В., Гончарова Е.В., Жузе В.П., Логинов Г.М., Сергеева В.М., Смирнов И.А. Физические свойства халькогенидов редкоземельных элементов. Л.: Наука, 1973. 304 с. 